\title{
Aulas investigativas e a construção de conceitos de matemática: um estudo a partir da teoria de Piaget ${ }^{1}$
}

\author{
Aline Silva de Bona ${ }^{a 1^{*}}$ \\ Maria Thereza Costa Coelho de Souzab \\ aInstituto Federal de Educação, Ciência e Tecnologia do Estado do Rio Grande do Sul (IFRS), \\ Departamento de Ensino de Matemática. Osório, RS, Brasil \\ ${ }^{b}$ Universidade de São Paulo, Instituto de Psicologia (IPUSP). São Paulo, SP, Brasil
}

\begin{abstract}
Resumo: 0 estudo é uma pesquisa qualitativa e colaborativa que tem o objetivo de compreender o processo de construção dos conceitos de Matemática dos estudantes por meio de atividades de investigação, pois pesquisas apontam que essas atividades mobilizam os estudantes a aprender de acordo com sua idade e amadurecimento. A fundamentação teórica foi a teoria de Piaget no que tange aos conceitos de equilibração e abstração reflexionante. O método constituiu-se da observação das aulas e atividades investigativas e das resoluções destas, realizadas em conjunto por seis estudantes do $6^{\circ}$ ano do Ensino Fundamental de uma escola municipal de Porto Alegre, em 2013. Os dados foram organizados em categorias relativas à interpretação, à resolução e à argumentação, articulando os elementos do cenário investigativo com o Método Clínico de Piaget. Destaca-se como resultado da pesquisa a compreensão da forma como os estudantes constroem o conceito de múltiplos e divisores de um número natural nessas aulas.
\end{abstract}

Palavras-chave: atividades, conceitos, ação, abstração, equilibração.

\section{Introdução}

A Matemática é uma ciência de notório saber considerada abstrata e muito difícil histórica e culturalmente. $\mathrm{Na}$ escola básica esta visão ainda permanece, pois os professores destacam que os estudantes não têm interesse em aprender Matemática por ser difícil, lamentando que as aulas são complicadas e que eles não entendem nada. Nesse sentido, segundo Fiorentini e Lorenzato (2007), D’Ambrósio (1996) e Bona (2012), é urgente estudar formas de mobilizar os estudantes a participar das aulas de Matemática, a fim de que se envolvam de forma ativa e realizem as atividades. Com o envolvimento do estudante, ocorre o desenvolvimento, e consequentemente se dá a aprendizagem, no caso da Matemática, contemplada na atividade.

Para despertar o interesse dos estudantes pelas aulas e atividades de Matemática, o professor precisa entender, ao menos um pouco, como o estudante aprende, e também quais são os pontos mais difíceis de cada conceito para construir e planejar suas aulas e atividades, de acordo com Dubinsky e Lewin (1986), e Bona e Leal (2013). Nesse sentido, também Nogueira e Pavanello (2008) destacam a necessidade de se estudarem possíveis intervenções

1 Este artigo é um recorte da pesquisa de pós-doutorado de uma das autoras em Psicologia Escolar e do Desenvolvimento Humano, do Instituto de Psicologia da Universidade de São Paulo, inserida na linha de pesquisa Desenvolvimento e Aprendizagem.

* Autora correspondente: aline.bona@osorio.ifrs.edu.br pedagógicas nas aulas de Matemática que sejam capazes de proporcionar aos estudantes abstrações reflexionantes, momentos de reflexionamento e reflexão adequados a seu ano escolar e idade, para assim desenvolver a construção do conhecimento de Matemática na escola básica.

A intervenção pedagógica adotada nesta pesquisa como cenário focal está alicerçada nas atividades de investigação, pois valem-se da ação dos estudantes e proporcionam a construção dos conceitos de Matemática (conhecimento), pois, segundo Bona e Leal (2013), Ponte, Brocardo e Oliveira (2006) e Piaget (1965/1973, 1970/1977), possibilitam o estudante a intuir, conjecturar, experimentar, provar, avaliar e apresentar os resultados encontrados. A ação de investigar significa compreender e procurar soluções para os problemas com os quais deparamos e assim descobrir relações, procurando sempre justificá-las.

As atividades de investigação contemplam elementos básicos como: (1) mobilização: ação que vise a mobilizar os estudantes a participar da aula e a partir dessa participação "aprenderem"; (2) aprendizagem: olhar sobre a aprendizagem dos estudantes e como compreendem esse aprender; (3) investigação: prática docente baseada no diálogo e na valorização das ações investigativas dos estudantes em sala de aula.

Com isso, este artigo tem por objetivo geral compreender o processo de construção dos conceitos de Matemática expostos por representações feitas pelos estudantes na aula investigativa proposta pelo professor em uma escola básica pública municipal da cidade de Porto Alegre. 
Inicialmente, realizou-se uma pesquisa-entrevista com professores de Matemática, de escolas públicas (municipais, estaduais e federais) e particulares de Porto Alegre, em busca de docentes que adotem tais atividades em sala de aula. Depois, observaram-se as aulas com a intenção de analisar os desenvolvimentos realizados pelos estudantes ao resolverem as atividades de investigação, e por fim, realizaram-se seis entrevistas com estudantes de duas turmas do $6^{\circ}$ ano do Ensino Fundamental. No processo de análise das observações coletivas, construíram-se três categorias (interpretação, resolução e argumentação) para compreender cada passo/representação da resolução da atividade. Tais categorias estão sustentadas nos conceitos de equilibração e abstração reflexionante de Piaget.

Assim, o artigo está organizado em seções: a primeira é a introdução, a segunda discute conceitualmente a equilibração e a abstração reflexionante neste cenário focal, e a terceira ilustra dados analisados na pesquisa por meio das falas transcritas dos estudantes entrevistados. Por fim, na quarta, os resultados, e na quinta as considerações finais e referências.

\section{A equilibração e a abstração reflexionante em atividades de investigação da Matemática}

A noção de equilibração é fundamental para a teoria de Piaget, porque todo o ser vivo procura manter um estado de equilíbrio-adaptação com o meio, agindo para superar perturbações na relação que se estabelece com o meio. Piaget (1972) define equilibração como um processo ativo de autorregulação que permite ao estudante eliminar as contradições, incompatibilidades e conflitos que surgem a partir de suas ações. Superar esses conflitos é desenvolver o conhecimento, e para isso se faz uso da assimilação.

O desenvolvimento cognitivo do indivíduo ocorre através de constantes adaptações, e cada adaptação possui dois componentes indissociáveis e complementares, que são a assimilação e a acomodação. A assimilação consiste na incorporação, pelo sujeito, de um elemento do mundo exterior às suas estruturas. $\mathrm{O}$ sujeito age sobre este elemento aplicando experiências anteriores ou esquemas. $\mathrm{Na}$ acomodação, se modifica a fim de se ajustar às diferenças impostas pelo meio. Esses componentes são pontos de partida para restabelecer o equilíbrio saltando de um patamar inferior para outro superior, que servirá de partida para as novas assimilações.

Desta forma, o equilíbrio é um estado de constantes trocas, só sendo possível porque as trocas entre sujeito e objeto garantem a conservação dos sistemas. Um é consequência do outro, porque o sujeito assimila características dos objetos, isto é, age sobre eles transformando-os em função dos esquemas de que dispõe. Os esquemas podem ser entendidos como pré-formas de ação, já compreendidas, que o organismo tende a repetir em diversas situações enquanto não encontra uma situação em que seja necessário adquirir novos esquemas de ação por aqueles não darem mais resultados.

Assim, os processos de ensino-aprendizagem na sala de aula e a premência de proporcionar atividades investigativas são fundamentais, pois geram os desequilíbrios necessários para instigar o raciocínio do estudante, facilitando a sua ação sobre o meio, sobre os objetos, sobre as ideias com os colegas, ou, ainda, por meio de experimentações, criar e solucionar problemas, observações, testagens e pesquisas. Instiga-o a sair do caminho trilhado, ousar, gerar o conhecimento real sobre o universo, não apenas pelo que ouviu o professor falar.

Nesse sentido, as etapas do desenvolvimento do estudante são influenciadas, de acordo com Piaget (1964), por quatro fatores principais: a maturação, o papel da experiência adquirida no meio físico sobre as estruturas da inteligência, a transmissão social em um sentido amplo (transmissão linguística, educação etc.) e o fundamental, a equilibração.

Em paralelo ao processo de equilibração se faz necessário pensar se a ação pela ação levaria a uma mudança a níveis mais elevados da inteligência. A partir dessa reflexão, Piaget (1970/1977) define abstração e seus tipos, além de suas relações com o conhecimento.

Para Bona (2012), o conhecimento não decorre da ação prática em si mesma, mas do que se pode abstrair e compreender das ações sobre os objetos. Daí a importância da tomada de consciência da ação, da compreensão das características do objeto e da significação do vivido em direção a novas operações ou a novos patamares de conhecimento, sendo que isso implica em abstração. Assim, a abstração está relacionada aos esquemas de assimilação do sujeito.

A abstração empírica, que se apoia sobre os objetos físicos ou os aspectos materiais da própria ação, como movimentos, segundo Piaget (1970/1977), fornece uma conceituação de certa forma descritiva dos dados de observação constatados nas características materiais da ação.

Já a abstração reflexiva "se apoia sobre as formas e todas as atividades cognitivas do sujeito, tais como os esquemas ou coordenações de ações, operações, estruturas e outras, para delas retirar certos caracteres e utilizá-los para outras finalidades, como novas adaptações ou novos problemas" (Piaget, 1970/1977, p. 6). A abstração retira das coordenações da ação o necessário para construir as coordenações inferenciais que, no nível do conceito, permitem ligar e interpretar esses dados de observação. Tais coordenações e o próprio processo reflexionante podem permanecer inconscientes ou provocar tomadas de consciência e conceituações distintas.

Entretanto, quando o objeto é transformado pelas ações do sujeito e enriquecido por propriedades retiradas de suas coordenações, tem-se um caso particular de abstração reflexionante, denominado abstração pseudoempírica. Para Piaget (1970/1977), a abstração pseudoempírica acontece porque ao agir sobre o objeto e sobre seus observáveis atuais, as constatações, de forma semelhante ao que acontece 
na abstração empírica, alcançam os produtos da coordenação das ações do sujeito. A abstração refletida é o resultado de uma abstração reflexionante após tornar-se consciente. Portanto, a abstração reflexionante comporta dois aspectos essenciais: o reflexionamento, que é a projeção daquilo que foi retirado de um patamar inferior sobre um patamar superior, e a reflexão, que pode ser compreendida como o ato mental de reconstrução e reorganização sobre o patamar superior do que foi transferido a partir do inferior.

A partir de abstrações reflexionantes, como o pensamento formal age retroativamente sobre as construções dos níveis anteriores, a conceituação passa a modificar a ação e não se tem mais o atraso da conceituação sobre a ação. Segundo Piaget e Inhelder (1976), "o pensamento formal é essencialmente hipotético-dedutivo. A dedução não mais se refere diretamente a realidades percebidas, mas a enunciados hipotéticos. Ocorre uma inversão de sentido entre o real e o possível" (pp. 205-206).

Sendo assim, a abstração será maior ou menor dependendo do contexto em que o estudante esteja inserido. O contexto serve para alimentar as experiências anteriores ou os esquemas. Portanto, a preocupação em apresentar atividades que contemplem a ação de investigar dos estudantes para a construção dos conceitos de Matemática deve ser frequente. Assim, a ação torna-se fundamental no processo pedagógico, pois torna viável a experiência, que possibilita as mudanças de esquemas, e essa ação pode estar relacionada à realização de algo concreto e ao mesmo tempo interpretativo.

Piaget (1967/1980) define a Matemática como um "sistema de construções que se apoiam igualmente, nos seus pontos de partida, nas coordenações das ações e nas operações do sujeito e procedendo igualmente por uma sucessão de abstrações reflexionantes em níveis mais elevados" (p. 339). Do ponto de vista genético, para compreender o estatuto epistemológico do conhecimento matemático, importa buscar nos seus primórdios as conexões entre estruturas matemáticas nascentes e estruturas operatórias do sujeito (Nogueira \& Pavanello, 2008).

Quando Piaget compara uma criança a um matemático, refere-se à necessidade de que cada um tem de se desenvolver desde seu princípio, passando gradativamente pelos estádios, e para tal se fazem necessárias ações pedagógicas na escola capazes de despertar o interesse dessa criança-estudante em aprender. Dessa maneira, a articulação do conceito de investigação se enquadra perfeitamente nessa ideia, pois ao se pensar em investigar não necessariamente se tem a noção de uma "grande pesquisa científica". Entretanto, uma investigação pequena e simples na escola para um estudante de, por exemplo, 10 anos, é uma construção cognitiva equivalente a de um matemático ao provar um novo teorema que vem estudando. "Assim, a Matemática se constitui em um notável exemplo de construção do saber mediante a abstração reflexionante" (Nogueira \& Pavanello, 2008, p. 117).

Além disso, Dubinsky e Lewin (1986) destacam que os estudantes devem participar do processo de abstração, das resoluções das atividades, desde as mais simples até as de generalização, e não serem simplesmente expectadores do resultado. Estes autores ainda destacam que as atividades não devem ser apontadas pelo professor como triviais, pois isso proporciona uma sensação de incapacidade aos estudantes que ainda não entenderam. Tal destaque destes autores explica por que os estudantes muitas vezes não entendem ou acham a Matemática difícil: ficam apenas observando o professor fazer a resolução da atividade, ou seja, não estão participando do processo de abstração. Enfim, a abstração reflexionante é citada por Dubinsky e Lewin (1986), como "a forma de equilibração mais poderosa e cognitivamente mais interessante..., é aquela na qual uma estrutura cognitiva particular se reequilibra de um distúrbio, submetendo-se a um grau maior ou menos de reconstrução" (p. 61, tradução nossa) ${ }^{2}$.

Assim, os conceitos teóricos discutidos na seção 2 são usados como base para a análise da aula de Matemática explicitada na seção 3.

\section{Aula de Matemática: múltiplos e divisores de um número natural}

No primeiro semestre de 2013, após entrevista com o professor para ver se ele se enquadrava no cenário investigativo, observaram-se cinco dias de aula, sendo dois períodos de 50 minutos por dia de cada uma das duas turmas de $6^{\circ}$ ano do Ensino Fundamental.

O conceito de Matemática iniciado com os estudantes é o de múltiplos e divisores de um número natural. $\mathrm{O}$ professor tem um conjunto de atividades para trabalhar cada conceito, e nesta pesquisa analisam-se todas as atividades deste. No entanto, para fins deste artigo, faz-se um recorte de uma das atividades, e ilustra-se a entrevista de um dos seis estudantes entrevistados, com a finalidade de apontar e ilustrar a compreensão do estudante quanto ao conceito.

A atividade consistia num conjunto de peças de EVA, como um dominó, mas cujos números eram estrategicamente escolhidos pelo professor para que os estudantes pudessem explorar o conceito de Matemática em questão. A turma era quase todo dia organizada em grupos de quatro pessoas, tendo cada turma 28 estudantes com idade média de 11 anos. A dinâmica da aula era, primeiramente, tentar fazer a atividade com seu grupo com o professor orientando. Depois, cada grupo ia para o quadro e apresentava aos colegas e ao professor a sua resolução, com hipóteses, explicações, argumentos e provas. Neste momento, que era o mais rico da aula, todos os estudantes interagiam e tentavam realmente entender a resolução de cada grupo de colegas. Na maioria das vezes, cada grupo de estudantes desenvolvia e resolvia o problema de um jeito, ou seja, quando observavam a resolução dos colegas percebiam não ser a mesma que a do próprio grupo, ocorrendo assim

2 "The most powerful, and cognitively, the most interesting form of equilibration . . . is that in which particular cognitive strutures re-equilibrate to a disturbance by undergoing a greater or lesser degree of re-construction." 
uma troca de estratégias de resolução muito importante ao processo de abstração de cada estudante até se construir o conceito de Matemática.

Os estudantes mostraram gostar das aulas todos os dias, interagiam e falavam muito durante as resoluções, não tinham medo de errar ou de fazer perguntas, fosse ao professor ou aos colegas. O momento da socialização era o de maior alegria aos estudantes, pois ficavam sorrindo quando os colegas diziam compreender a resolução que tinham feito. Nesses momentos o professor observava e geralmente só interagia com questões objetivas, sempre procurando entender o que os estudantes pensavam, agindo com os estudantes como Piaget cita em seu método clínico, em busca do que pensavam para responder isso ou aquilo, naquele momento.

Para analisar as resoluções dos estudantes se fez necessário construir três categorias: (1) interpretação: compreende o que está sendo solicitado na atividade, usualmente faz sozinho e/ou com o grupo pequeno de trabalho de sala de aula; (2) resolução: de acordo com os dados da interpretação, descobre a(s) ferramenta(s) (conceitos) de Matemática para resolver a atividade com seu pequeno grupo de trabalho em sala de aula, além do professor enquanto propõe orientações e esclarece dúvidas; (3) argumentação: explicação e justificativas de cada ação/passo da resolução, geralmente feita com o grande grupo. Em cada categoria há indicadores para avaliar qualitativamente. No caso da interpretação e da resolução, as duas categorias são"plena" e "parcial"; já na categoria argumentação, avalia-se, além da classificação anterior, se o estudante argumenta de forma correta. A classificação divide-se em estratégia simples ou mais de uma estratégia.

A atividade 3 é um conjunto de oito questões abertas propostas aos estudantes, sendo as questões 1 e 2 centrais. Elas questionavam os estudantes quanto à capacidade de utilizar todas as peças, que são 34, de forma única, ou seja, há mais de uma forma de unir todas as peças em sequência de múltiplos e divisores.

A questão 2 perguntava se havia alguma peça coringa. Todos os estudantes entregaram o termo de livre consentimento esclarecido assinado pelos responsáveis, que gostaram da participação de seus filhos na pesquisa e de que o interesse tenha partido de cada estudante. A seguir transcrevem-se as falas do estudante A2 em entrevista:

Bom... primeiro pensei nas peças... são 42 números diferentes, já que 26 estão repetidos, dai tudo dá 34 vezes dois, igual a 42, mais 26, que dá 68. Quando fizemos na aula com colegas que distribuimos não temos controle das peças, mas em casa sozinho fiz mais de uma vez usando tudo. Mas pensei em organizar todos os números primeiro. Os que dividem por dois: 2, 4, 6, 8, 10, 12, 14, 16, 18, 20, 22, 24, 28, 30, 32, 36, 42, 48, 50, 54, 56, 60, 64, 70, 72. Dai os que dividem por três: 3, 6, 9, 12, 15, 18, 21, 24, 27, $30,36,39,42,45,48,54,60,63,72,81$, e o maior número é 81 , e o menor 1, e vem os que dividem por cinco: $5,10,15,20,25,30,35,45,50,60,70$, depois os de sete: 7, 14, 21, 28, 35, 42, 49, 56, 63, 70. Contei que o 7 repete 5 vezes, o 5 e o 3 repetem 4 vezes, e o 2 apenas 2 vezes, assim como outros... então comecei a mexer nas peças e ver que tudo depende de usar os números grandes no começo e os números -problema como 49, que só tem 1, 7 e ele. Pensando mais, usei os primos 13 e 11, que só se relacionam com 39 e 22. Dai fui fazendo, sempre olhando as peças que ficavam e sempre olhando o 7, porque ele se liga com a maioria. Agora o zero é um número, logo ele estraga tudo se tiver no jogo, porque faz ficar falso de um lado, só vai valer para múltiplo, já que ele não é divisor. E sempre que pensar nos grande estamos pensando mais em múltiplos, como expliquei na aula depois que fizemos a primeira vez, isso foi o mais fácil de ver com os colegas mesmo, que fazer a conta de dividir com as peças que temos na mão parece mais fácil. A peça do um eu chamaria de coringa... um é divisor de todos. Mas ter peças grandes repetidas para se juntar por todo número ser múltiplo não tem exercício e nem conta para fazer, e estas peças tipo 72 e 3 tem que pensar, e eu disse para o professor que meu grupo fez, seria legal escrever a lista dos resultados lendo de um jeito e dai descobrir as peças.

A primeira observação a ser feita em relação ao estudante é seu entusiasmo em resolver a atividade, pois responde quase todas as questões de uma só vez e é tão concentrado no que faz, que foi lendo as questões e respondendo, como transcrito acima, além de ir construindo uma das soluções que fez em casa com suas peças, que trouxe. $\mathrm{O}$ amadurecimento do estudante quanto a sua responsabilidade com o processo de aprendizagem pode ser exemplificado nas passagens grifadas na citação anterior, algumas ações do estudante.

Na transcrição percebe-se a compreensão do estudante quanto às três categorias: interpretação, resolução e argumentação. A compreensão conceitual de múltiplos e divisores de um número natural é bem visível nas suas falas e ações, inclusive por coordenações complexas e por novos esquemas de assimilação, desde os provocados pelos colegas em sala de aula que agora o estudante anima-se a usar, e até trocar pelos seus esquemas antigos.

A construção feita pelo estudante A1, de entrevista anterior ao A2, estava em outra mesa, porque a sala dos professores, local onde foram realizadas as entrevistas, é composta de três mesas redondas com quatro cadeiras cada, e mais uma mesa retangular grande com 12 lugares de forma central na sala. Estávamos entrevistando o estudante A2 na mesa perto da porta, onde ele chegou e sentou, e não perto de onde estávamos com o estudante A1, nos obrigando a ir até ele. Quando anotávamos algumas observações de sua fala, o estudante olhou para a sala dos professores como um todo e disse: "Posso ver aquela mesa?", que apontava para a construção da colega A1, e 
foi se levantando. Esse fato aponta para a necessidade de apropriação do espaço como um fator importante para esse estudante.

Aproveitamos essa oportunidade para perguntar o que o estudante tentava dizer na sua última frase, transcrita anteriormente, e assim o pedimos para que exemplificasse, nessa construção, sua ideia sobre a lista dos resultados. A resposta do estudante foi:

Professora, olha para cá [dedo apontando para o fim da sequência], lendo isso dá: 2 é divisor de 6, 6 é múltiplo 3, 3 é divisor de 15, 7 é divisor de 21, 12 é múltiplo de 4, 18 é divisor de 72, 3 é divisor de 27, 6 é divisor de 24, 50 é múltiplo de 25, 2 é divisor de 10, 16 é múltiplo de 8 . ., agora veja os resultados, $D$ (divisor), $M$ (múltiplo), $D, D, M, D, D, D$, $M, D, M$. . . com isso dá para fazer uma sequência diferente desta ainda. . . A professora sabe que o professor faz tudo ficar tão fácil com estas atividades que eu até não tenho mais medo de matemática e nem acho tão difícil.

Quando esse estudante consegue explicar, em outra situação, que não foi ele quem construiu, reflete sobre a reversibilidade conceitual da Matemática e ainda de seus pensamentos, pois o fato de aplicar em outra situação demonstra que compreendeu adequadamente o conceito de Matemática, inclusive explicado por uma linguagem Matemática própria, como a fala transcrita evidencia. Essa ação complementa ainda mais a categoria argumentação, por sua diversidade de estratégias.

Ainda, observando a construção do estudante A1, o estudante A2 diz:

Se invertermos a posição da peça 8 e 32, ainda estará certo, porque o 8 tava ligado no 16 e o 32 também, como 8 é divisor de 16 e de 32, e ambos são múltiplos de 8, e 16 é divisor de 32, e este múltiplo de 16. Legal. A professora sabe que no теи grupo uma colega juntou 72 e 64, e depois 27 e 6 ... ela não tinha entendido bem o que era múltiplo, ela achou que era só ter um número que divide os dois juntos, tipo no 6 e 27 o 3, mas a gente ajudou ela, e no quadro mais colegas também tinham feito esta confusão.

Nessa transcrição, quando consegue trocar as peças de lugar, o estudante A2 demonstra uma abstração refletida, pois consegue generalizar o pensamento e ainda revertê-lo corretamente. Depois, quando o estudante A2 destaca um erro comum de sua colega, evidencia que compreende o conceito de fatores múltiplos e o distingue do que é ser apenas múltiplo de um número. $\mathrm{O}$ fato de que esta distinção somente será trabalhada mais tarde pelo professor de Matemática aponta para o que Piaget diz sobre o estudante tornar-se um matemático em aulas com intervenções pedagógicas adequadas, por conseguir descobrir conceitos como se não existissem antes. Um exercício do tipo "siga o modelo" não proporcionaria tal desenvolvimento a esse estudante.

De acordo com a idade desse estudante e dos estádios de Piaget, ele está precocemente adiantado, pois estabelece coordenações formais para além de seu amadurecimento. Essa consideração torna a teoria de Piaget ainda mais aplicável aos professores, já que o progresso dos estudantes varia entre estes e pode ser compreendido através das abstrações reflexionantes. Além disso, a construção de conhecimento do estudante é benéfica aos colegas também de uma forma natural e afetiva, porque a socialização possibilita que o adiantamento seja possível a todos os que estiverem amadurecidos, e para os que ainda não, ao menos para não se sentirem em desequilíbrio a buscar a assimilação.

A entrevista com o estudante A2 foi muito interessante, porque o entrevistado foi conversando sobre tudo o que gostou na atividade e no que os colegas explicaram em aula, respondendo a tudo corretamente e falando sempre muito baixo. Por fim, disse:

A professora está fazendo este trabalho com a gente por quê? Meu pai disse que nossa escola é especial, já que moramos numa zona complicada de violência e ainda conseguimos estudar, por isso a senhora nos escolheu. Ele ficou contente que eu me ofereci para fazer a pesquisa com a senhora. Disse também que a senhora, que vem da faculdade, faz coisas para melhorar as aulas nas escolas, é?

A fala final de A2 mostra o envolvimento de sua família com os estudantes e sua preocupação com a escola e com o coletivo.

\section{Resultados}

Os dados quantitativos, assim como os qualitativos, evidenciam como os estudantes compreendem/constroem o conceito de múltiplo e divisor de um número natural por meio desta atividade de investigação, conforme apresentado na Tabela 1.

Tabela 1

Dados descritivos distribuidos por categorias

\begin{tabular}{c|c|c|c}
\hline $\begin{array}{c}\text { Categorias/ } \\
\text { turma- } \\
\text {-estudantes }\end{array}$ & $\begin{array}{c}\text { Compreendem } \\
\text { plenamente }\end{array}$ & $\begin{array}{c}\text { Compreendem } \\
\text { parcialmente }\end{array}$ & $\begin{array}{c}\text { Somente os } \\
\text { entrevis- } \\
\text { tados com } \\
\text { compreensão } \\
\text { plena }\end{array}$ \\
\hline Interpretação & $57 / 58$ & $1 / 58$ & $6 / 6$ \\
\hline Resolução & $54 / 58$ & $4 / 58$ & $5 / 6$ \\
\hline Argumentação & $52 / 58$ & $5 / 58$ & $6 / 6$ \\
\hline
\end{tabular}

Depois da análise das resoluções coletivas/individuais, apontam-se três estratégias de resolução, que são 
evidenciadas na categoria da argumentação, sendo contempladas primeiramente na categoria resolução e depois argumentação, já que entender o que era para ser feito na atividade foi plenamente interpretado por todos das duas turmas: a) a primeira, identificada pela maioria dos estudantes e mais presente em seus grupos, é a da tabuada; b) a segunda é fazer os cálculos, já que em alguns grupos os estudantes faziam as contas em papéis de rascunho a cada vez em que era a vez deles de colocar uma peça; c) a terceira é observar as peças de maior valor primeiro e as descartar no início, depois as peças com números repetidos.

Todas as estratégias são traçadas sobre ações de abstração reflexionante de forma geral em diferentes patamares, mas as ações de alguns estudantes são pseudoempíricas, e outros já estão em patamares mais avançados de abstração reflexionante, porque são coordenações que se estabelecem não pela ação com os objetos, mas por relações que independem dos objetos. Todos os grupos das duas turmas usaram primeiro a estratégia da tabuada para os números e os cálculos para os números maiores. A maioria dos estudantes identifica a tabuada como a ferramenta possível para resolver a atividade, sentindo-se familiarizada com os esquemas de assimilação, e quando não encontra a solução na tabuada, busca outras ferramentas ainda mais antigas, como a operação de multiplicação, até chegar ao resultado.

Dessa forma, a Tabela 2 mostra quantitativamente as resoluções por estratégias na categoria da argumentação, sendo um conjunto de resultados primordiais. Por exemplo, é possível constatar que a maioria dos estudantes percebeu mais de uma forma de resolver o exercício quando o fez de forma coletiva. Isto é, esses estudantes em um grupo pequeno já conquistaram uma resolução, mas as outras formas de resolver são compreendidas apenas com o coletivo.

Dos estudantes entrevistados, apenas um ficou limitado a uma estratégia de resolução, que no entanto aponta para um progresso, já que ele tem muitas dificuldades com a operação de multiplicação dos números naturais. Este é um dos conceitos básicos para múltiplos/divisores, e ter encontrado uma estratégia significa que supera a dificuldade conceitual anterior.

Tabela 2

Dados descritivos distribuídos na categoria Argumentação

\begin{tabular}{cccc}
\hline $\begin{array}{c}\text { Categoria } \\
\text { estumentação/ }\end{array}$ & $\begin{array}{c}\text { Resolução } \\
\text { individual } \\
\text { e em seu } \\
\text { pequeno } \\
\text { grupo }\end{array}$ & $\begin{array}{c}\text { Resoluções } \\
\text { coletivas } \\
\text { com a } \\
\text { turma }\end{array}$ & Entrevistados \\
\hline $\begin{array}{c}\text { Estratégia } \\
\text { simples }\end{array}$ & $27 / 52$ & $10 / 52$ & $1 / 6$ \\
\hline $\begin{array}{c}\text { Mais de uma } \\
\text { estratégia }\end{array}$ & $25 / 52$ & $42 / 52$ & $5 / 6$ \\
\hline
\end{tabular}

Os dados qualitativos são ricos, como o estudante A2 ilustra na seção anterior. Portanto, é fundamental destacar de forma objetiva que o cenário das aulas investigativas é possível na escola básica e que proporciona o desenvolvimento do estudante como sujeito do próprio processo de aprendizagem, mobilizando-o cada vez mais a participar e se envolver com as atividades das aulas de Matemática. Isso acontece tanto pela interação com os colegas e professor como pela autonomia e liberdade que lhes é possibilitada, fator atrativo à idade dos estudantes.

Em paralelo a esse cenário é possível compreender e avaliar o processo de construção dos conceitos de Matemática expostos pelas representações feitas pelos estudantes na aula investigativa, objetivo desta pesquisa-ação.

A compreensão do processo de construção dos conceitos de Matemática é feita através da análise de um conjunto de atividades em que os estudantes agem. As ações são transcritas em sala de aula com o grupo ou em entrevistas, sustentadas, inicialmente, pela desestabilização dos estudantes na busca por conseguir construir e manipular as peças, responder às questões e aos problemas. A cada interação se avalia o tipo da ação segundo seu tipo de abstração: empírica, reflexionante, pseudoempírica ou refletida.

Analisa-se de forma geral, como descrito nas seções anteriores, a atividade coletiva como um passo fundamental e desencadeador da curiosidade dos estudantes para realizar a atividade, para buscar esquemas de assimilação a fim de entender suas próprias ideias e a dos colegas de pequenos grupos, que no começo é categoria da interpretação presente e compreendida, para dar sequência à resolução.

$\mathrm{Na}$ resolução, a presença do professor questionador em vez de exemplificador faz que os estudantes tentem descobrir a solução entre si, mesmo que de forma aleatória, por tentativa, muitas vezes sustentada em operações concretas baseadas nas peças. Mas ao momento que surgem as estratégias (manipulação da tabuada, ideia de realizar cálculos e depois a conceituação de que a divisão entre múltiplo e divisor deve ter resto zero), os pensamentos dos estudantes se tornam operações e coordenações além das peças, surgindo também a necessidade de continuidade, presente pelo reflexionamento, e generalização, construída na reflexão, elementos que compõem a abstração reflexionante. É nesse processo de abstrações reflexionantes em forma de espiral que se desencadeia o conhecimento em cada estudante. Entretanto, é no fechamento desse desencadeamento que a reflexão se torna mais destacada, ao ter necessidade de argumentar suas conjeturas e resoluções, agora não somente a seu pequeno grupo, mas à turma e ao professor. Esse é o momento de uma construção em tempo real, porque muitas vezes os estudantes resolviam o problema de forma certa, conseguiam explicar o que e como pensavam, mas precisavam refletir com os colegas ao escutarem sua própria fala e suas ações, para compreendê-las. Era possível "ver" a construção conceitual dos estudantes no quadro explicando suas ideias.

Algumas dessas dificuldades eram adequadas à idade e ao estádio em que esses estudantes se encontravam, sendo os obstáculos concretos completamente superados Isso acontecia porque, no quadro, os estudantes explicavam sem as peças aos colegas, ou seja, argumentavam com 
suas palavras conceituações de Matemática, muitas dessas contemplando a reversalidade. Desse coletivo, as atividades que seguem predominam cada vez mais generalização dos pensamentos até a formalização conceitual. Um dos objetivos da aula de Matemática é proporcionar aos estudantes o aprendizado de conceitos de aplicação múltipla e sua padronização em diversas situações.

Analisando as resoluções dos estudantes entrevistados na atividade 3 em relação às coletivas, já é possível avaliar um progresso conceitual de Matemática por meio das representações usadas pelos estudante em suas falas. Ao invés de apontar a peça e pensar na tabuada para dizer que 54 é múltiplo 6, os estudantes simplesmente destacam que "54 tem os divisores primos 2 e 3, e assim 6, 9 e 27 são seus divisores também", atingindo uma amplitude de compreensão além da estratégia da tabuada e da simples divisão para ver se resultará certo.

A atividade 3 é a mais densa e complexa pelo fato de as questões serem abertas, já que "usar todas as peças" implica em muitas soluções e formas de resolver o problema, além das estratégias, e como coordenar as ações com os colegas para que todos participem, sem brigas e com respeito, e que assim a resposta seja encontrada. Pelas transcrições individuais é notória a variedade de pensamentos e formas de representar o mesmo conceito de Matemática, mas toda essa variedade decorre de cada estudante pensar de uma forma e ter seus esquemas de assimilação, acomodando, assim, e valendo-se do seu tempo de autorregulação para dar sequência à resolução, seja por uma ação que faz correspondência à ação de um colega ou até sua complementaridade.

A interpretação é uma categoria chave para o pensamento matemático, porque se não se entende o que é para fazer, não se sabe como buscar internamente a ferramenta para resolver. Essa interpretação é realizada com muito sucesso pela maioria dos estudantes, como mostra a tabela de frequência em dados quantitativos e as falas analisadas das demais atividades.

A resolução é o processo mais longo, sendo assim a categoria em que há mais possibilidade de haver diversidade, seja coletiva ou individual. Entretanto, proporciona ao professor de Matemática entender as dificuldades dos estudantes e, inclusive, identificar os "conceitos pré-requisitos", tão falados em Matemática. Estes conceitos na realidade não estão presentes se o estudante não os aprendeu, seja porque o professor não ensinou ou porque o aluno apenas "decorou", e agora, em outra situação, desconhece-os.

Na resolução verificam-se os tipos e variedades de abstrações reflexionantes com seus elementos muito claros, sendo viável ao professor-pesquisador compreender como os estudantes construíram os conceitos em uma situação particular para as autoras desta pesquisa, que não são professoras de Matemática e estavam apenas observando a ação construtiva da sala de aula. A instabilidade e curiosidade dos estudantes em resolver e entender as ideias dos colegas é fascinante pela idade e pelo desenvolvimento crescente deles, perceptível de uma atividade para a outra, tanto como seres humanos no geral como no aspecto cognitivo.
A necessidade dos estudantes de ilustrar seus pensamentos e resoluções com as peças é característica de sua idade e estádio predominante, em que ainda se tem muito interesse pelo concreto, no caso, as peças da atividade. Isso não atrapalha, pelo contrário, auxilia e proporciona segurança afetiva aos estudantes, ao pensarem melhor sobre as resoluções. Além disso, as peças e a dinâmica do professor para a atividade proporcionam uma interação mais próxima com os colegas, o que permite manuseio e ações conjuntas, como fica evidente na construção das peças, tanto aos que fizeram em aula como aos que fizeram em casa.

A ação de socializar as ideias e resoluções é uma atitude que parece influenciar na autoestima dos estudantes perante o grupo, pois se encontram em uma idade em que é importante ser aceito e reconhecido pelo grupo. Isso também se dá na capacidade de aprender, pois os estudantes se "consideram" entre si (ou seja, eles se respeitam e consideram relevantes as opiniões uns dos outros) com falas simples, como esses exemplos: "legal que conseguimos, somos espertos", "valeu pela ajuda na hora que estava confuso" e "achei tão legal que você entendeu o que expliquei e usou com o professor".

O processo de compreensão da construção conceitual dos estudantes finaliza-se articulando este desenvolvimento no grupo e em si mesmos, em um crescente visível nas atividades por meio das resoluções e argumentações cada vez mais completas, corretas e de diversas estratégias possíveis. Assim, é possível afirmar que se avalia positivamente a compreensão dos estudantes quanto ao conceito de múltiplos e divisores de um número natural, além de outros conceitos (como números primos, por exemplo, que não estão previstos no ano letivo, e a iniciação dos estudantes nos critérios de divisibilidade e fatores de um número, previstos para mais adiante no ano letivo).

A categoria da argumentação é a mais característica deste cenário investigativo, e é a ação que potencializa a reflexão dos estudantes, tanto pela necessidade de verbalizar e explicar como pensaram quanto em fazer seus colegas os compreenderem. Um terceiro momento é o estudante entender o que seu colega resolveu e verificar a possibilidade de soluções diferentes com a mesma resposta correta para um mesmo problema. É importante destacar que se analisar apenas a resolução o estudante pode saber fazer e não saber explicar, assim como seu grupo pequeno. Saber fazer o exercício e explicar sua resolução torna o processo de aprendizado mais completo. É possível avaliar a compreensão que os estudantes têm nessa articulação de categorias, que os próprios demonstram entender que são momentos em que se complementam.

\section{Considerações finais}

Os resultados desta pesquisa foram satisfatórios para o professor de Matemática da escola, que demonstrou ter ficado feliz conversando, para os estudantes, após as resoluções das atividades, e para as pesquisadoras. Percebe-se um professor que compreende o cenário 
estudado como mais adequado para a construção dos conceitos de Matemática do que apenas quando motivado por sua vontade de ensinar, como ele mesmo diz. Quanto aos estudantes, os resultados são ótimos, pois, segundo suas falas sobre o professor e suas aulas, sentem-me mobilizados, ativos e aprendendo a matéria. É fundamental que os estudantes tomem consciência de si mesmos sobre as aulas de Matemática.

Quanto à pesquisa-ação, os resultados apontam para categorias construídas como satisfatórias para compreender o processo de construção conceitual dos estudantes, sendo possível ao professor apenas pensar nessas três categorias para avaliar formativamente os estudantes e suas aulas; quanto para um estudo da área do desenvolvimento, e consequentemente da aprendizagem, inserido no contexto da Psicologia, como esta pesquisa.

No que tange à Teoria de Piaget, é aplicável a compreensão e avaliação da construção dos conceitos de Matemática tendo como base a equilibração e a abstração reflexionante, ambos elementos fundamentais para a construção de conhecimentos dos estudantes, como apontados nesta pesquisa. Compreender esse processo de equilibração articulado às ações de abstração reflexionante faz com que se olhe para o estudante com mais cuidado. Leva-se em conta sua idade e amadurecimento, não somente uma lista de conteúdos que precisam ser trabalhados, desde a adaptação ao contexto até uma diversidade de formas e meios de trabalhar esses conceitos, como fez o professor com peças, perguntas abertas e fechadas, e, por fim, problemas.

$\mathrm{O}$ que Piaget aponta no Método Clínico de conversar com as crianças no cenário das investigações é o diálogo entre professor e estudantes e entre os próprios estudantes a fim de que cada um apresente a sua forma de pensar. Assim, quando os estudantes apresentam suas resoluções aos colegas e professor e todos podem fazer questões com a intenção de entender o que pensam, se mostra a conversa de Piaget em busca de compreender o que pensam. Contemplar essa ação de ouvir e dialogar com os estudantes é um elemento central para que a escola básica incorpore e melhore o processo de desenvolvimento/aprendizagem dos estudantes, em especial em Matemática, que culturalmente os estudantes têm medo até de perguntar.

Outro aspecto central destacado por Piaget é a linguagem simbólica da Matemática, que deve ser a última etapa de atividade para os estudantes, como apoia esse professor e é sugerido nas conceituações de práticas investigativas. Particularmente nessa idade em que os estudantes se encontram, do estádio operatório ao formal, essa não compreensão do que está escrito no exercício recai sobre as categorias de interpretação e resolução que limitam o estudante a participar da atividade. Desta forma, se os estudantes não conseguem participar, não conseguiram entender consequentemente.

Nesse sentido, valorizar as formas com que os estudantes expressam suas ideias e pensamentos, seja por desenhos, palavras e/ou exemplos concretos ou gerais são importantes para os novos esquemas de assimilação. Ao mesmo tempo, as dificuldades tdevem ser encaradas como momentos normais da resolução da atividade, como ocorreu com o estudante da pesquisa que ajudou o colega no fator comum e assim deu seguimento, pois essa ação com a dificuldade proporciona ao estudante que errou um novo esquema de assimilação, completo e correto, e não parcial e ainda não acomodado como o esquema que estava errado.

Mais uma vez fica evidente a necessidade de diversificar as atividades de Matemática para proporcionar aos estudantes momentos variados e adequados ao tempo de aprendizagem individual, em que cada uma de suas representações seja passível de observação e análise pelo professor. Aponta-se aqui a necessidade formação continuada do docente que contemple a Psicologia do Desenvolvimento e da Aprendizagem como matéria essencial ao professor a fim de melhorar a qualidade da educação de Matemática na escola básica e desta forma torná-la um espaço atrativo aos estudantes de hoje.

\section{Investigative classes and construction of concepts of mathematics: a study of Piaget's theory}

Abstract: The study is a qualitative and collaborative research that aims to understand the construction process of concepts of mathematics students through research activities, as the research indicates that these activities mobilize students to learn according to their age and maturity. The theoretical framework was Piaget's theory in relation to concepts of equilibration and reflective abstraction. The method consisted of observation of classes and investigative activities and its resolutions collectively done by six students from the $6^{\text {th }}$ grade of a public school in Porto Alegre, in 2013. The data were organized into categories relating to interpretation and argument resolution, articulating the elements of investigative scenario with Piaget's Clinical Method. It stands out as a result of research, the understanding of how students construct the concept of multiple divisors of a natural number in these classes.

Keywords: activities, concepts, action, abstraction, equilibration.

\section{Des cours investigatifs et la construction des concepts de mathématiques: une étude de la théorie de Piaget}

Résumé: Cette étude est une recherche collaborative et qualitative, qui vise à comprendre le processus de construction des concepts d'étudiants en mathématiques à travers les activités d'investigation, car les recherches indiquent que ces activités 
encouragent les étudiants à apprendre en fonction de leur âge et maturité. Le cadre théorique a été la théorie de Piaget concernant les concepts d'équilibre et d'abstraction réfléchissante. On a utilisé la méthode d'observation des cours et d'activités d'enquête et résolutions realisées par six élèves ensemble, étudiants d'une école primaire publique à Porto Alegre, en 2013. Les données ont été organisés en catégories liées à l'interprétation, la résolution et l'argumentation, en articulant les éléments du scénario d'investigation avec la Méthode Clinique de Piaget. Comme résultat de la recherche, on met en évidence la compréhension de la façon dont les élèves construisent le concept de multiples et diviseurs d'un nombre naturel dans ces cours.

Mots-clés: activités, concepts, action, abstraction, équilibrage.

\section{Clases investigativas y la construcción de conceptos de matemáticas: un estudio a partir de la teoría de Piaget}

Resumen: Este estudio es una investigación cualitativa y colaborativa, que tiene como objetivo comprender el proceso de construcción de los conceptos de matemáticas de los estudiantes mediante actividades de investigación, pues pesquisas indican que esas actividades movilizan los estudiantes a aprender de acuerdo a su edad y madurez. La fundamentación teórica fue la teoría de Piaget sobre los conceptos de equilibrio y la abstracción reflexionante. El método utilizado fue la observación de clases, actividades de investigación y resoluciones de seis estudiantes agrupados del $6^{\circ}$ año de la educación primaria de una escuela municipal de Porto Alegre en 2013. Los datos fueron organizados en categorías relativas a interpretación, resolución y argumentación, articulando los elementos del escenario investigativo con el Método Clínico de Piaget. El resultado de la pesquisa fue la comprensión de cómo los estudiantes construyen el concepto de múltiplos y divisores de un número natural en las clases.

Palabras clave: actividades, conceptos, acción, abstracción, equilibrio.

\section{Referências}

Bona, A. S. (2012). Espaço de aprendizagem digital da matemática: o aprender a aprender por cooperação (Tese de doutorado). Programa de Pós-Graduação em Informática na Educação, Universidade Federal do Rio Grande do Sul. Porto Alegre.

Bona, A. S., \& Leal, L. B. (2013). Novas práticas investigativas nas aulas de matemática. In $X V$ Encontro Nacional de Educação Matemática (pp. 1-15). Curitiba, PR.

D'Ambrosio, U. (1996). Educação matemática: da teoria a práxis. Coleção Perspectivas em Educação Matemática. Campinas, SP: Papirus.

Dubinsky, E., \& Lewin, P. (1986). Reflective abstraction and mathematics education: the genetic decomposition of induction and compactness. The Journal of Mathematical Behavior, 5(1), 55-92.

Fiorentini, D., \& Lorenzato, S. (2007). Investigação em educação matemática: percursos teóricos e metodológicos. Campinas, SP: Autores Associados.

Nogueira, C. M. I., \& Pavanello, R. M. (2008). A abstração reflexionante e a produção do conhecimento matemático. Revista Bolema, (30), 111-130.
Piaget, J. (1964). Development and learning. Journal of Research in Science Teaching, 2(3), 176-186.

Piaget, J. (1972). Development and learning. In C. S. Lavattelly, \& F. Stendler. Reading in child behavior and development. Nova York, NY: Hartcourt Brace Janovich.

Piaget, J. (1973). Estudos sociológicos. Rio de Janeiro, RJ: Forense. (Trabalho original publicado em 1965).

Piaget, J. (1977). Abstração reflexionante: relações lógicoaritméticas e ordem das relações espaciais. Porto Alegre, RS: Artmed. (Trabalho original publicado em 1970).

Piaget, J. (1980). Lógica e conhecimento cientifico. Porto, Portugal: Civilização. (Trabalho original publicado em 1967).

Piaget, J., \& Inhelder, B. (1976). Da lógica da criança à lógica do adolescente. São Paulo, SP: Pioneira.

Ponte, J. P., Brocardo, J., \& Oliveira, H. (2006). Investigações matemáticas na sala de aula. Belo Horizonte, MG: Autêntica. 